\title{
Design of a milling reactor coupled to a high-temperature mass spectrometer for thermodynamic/kinetic data of hydrogen-based materials
}

\author{
A. El Kharbachi, ${ }^{a, b}$ I. Nuta, ${ }^{a^{*}}$ L. Artaud, ${ }^{a}$ H. Collas, ${ }^{a}$ and C. Chatillon ${ }^{\text {a }}$ \\ (a) Univ. Grenoble Alpes, CNRS, Grenoble INP*, SIMaP, 38000 Grenoble, France \\ (b) Helmholtz Institute Ulm (HIU), Helmholtzstr. 11, 89081 Ulm, Germany
}

Corresponding Author: Ioana.Nuta@grenoble-inp.fr

\begin{abstract}
Identification of species in the gaseous phase of hydride materials and their mixtures (e.g. $\mathrm{LiBH}_{4}-$ $\mathrm{MgH}_{2}$ ) is crucial for understanding the reactional mechanisms and diffusion kinetics of hydrogen across the different interfaces of phase segregation. This phase separation makes the characterization by conventional gas analysis techniques complicated and some analytical information could not be accessible. To overcome this surface/interface related issue, the study of the evolution of the gas phase emitted by the complex hydrides during ball-milling is considered. In this respect, an experimental setup is designed by coupling a milling reactor with a mass spectrometer through a capillary tubing and an effusion Knudsen cell. A gas flow study (from molecular to viscous regimes) is performed in order to propose a suitable architecture of the entire device (ball-mill, capillary tubing, pipes, effusion cell compartment and pumping system) compatible with the mass spectrometric detection in terms of effused flow and molecular beam. Simulation of the flows and definition of their regimes nature at each stage of the pipes and vessels system is addressed as function of geometric parameters, upstream pressures, and pumping capacity on the downstream side (effusion cell). The study highlights the advantage of using a capillary tubing for the connection and ensure an optimal detection. Different working pressure conditions are demonstrated and associated to its length, meanwhile the diameter of the capillary has been demonstrated to be too sensitive to be varied.
\end{abstract}

Keywords: Flow calculations; metal hydrides, vapor pressure; mass spectrometry, experimental device 


\section{Introduction}

The study of the chemical reactions of decomposition or recombination of the complex hydrides is of utmost importance to reach sustainable and efficient energy storage materials [1,2]. Among the possible rate-limiting steps, the two models presented in Fig. 1 where the desorption of $\mathrm{MgH}_{2}$ could be limited by the formation of $\mathrm{Mg}$ layers around the particles, and vice-versa during the absorption of hydrogen [3-5]. The following equilibrium reaction (solid-gas) illustrates a case of a simple reaction of a metal hydride $\left(\mathrm{MgH}_{2}\right)$ :

$$
\mathrm{MgH}_{2}(\mathrm{~s}) \longleftrightarrow \mathrm{Mg}(\mathrm{s})+\mathrm{H}_{2}(\mathrm{~g})
$$

Vapor pressure measurements of compounds under mechanical constraints, i.e. during the milling process, can contribute to the understanding of interface effects on the rate of formation of the gaseous species. The desorption kinetics can be increased by reactive milling meanwhile the $\mathrm{H}_{2}$ pressure moves toward equilibrium. Similar behavior is predictable for absorption under milling, where hydrogen intensities that can be measured by mass spectrometry decrease in time. For more complex hydrides such as $\mathrm{LiBH}_{4}(\mathrm{~s})$, in addition to hydrogen it is expected that $\mathrm{BH}_{3}(\mathrm{~g})$ and $\mathrm{LiH}(\mathrm{g})$ gas molecules can be observed [6,7], as well as more complex species $\mathrm{B}_{\mathrm{n}} \mathrm{H}_{\mathrm{m}}(\mathrm{g})$ already reported using mass spectrometry during heating $[6,8]$.

In order to carry out measurements of vapor pressures under "mechanical activation" at slow reactional kinetics and quasi-equilibrium, a design study of the coupling of the milling reactor to a mass spectrometer is necessary. This consists of connecting a ball-milling device working at atmospheric pressures to a mass spectrometer in which the ionization chamber is maintained under vacuum (UHV). The mass spectrometer was selected to be associated to the milling reactor, through an especially designed effusion cell, for the following main reasons:

- A great sensitivity of detection can be reached for a dynamic pressure range of $10^{-5}-10^{-6}$ bar in the effusion cell, depending on the observed species nature

$\circ$ A high resolution of about 800 at $10 \%$ valley which is reached with our single magnetic prism is sufficient to separate almost completely all the observed species

- A reliable shutter of the molecular beam is essential to ensure optimal detection of condensable vapors especially for "permanent" gases $\left(\mathrm{H}_{2}, \mathrm{~N}_{2}\right.$ and $\left.\mathrm{Ar}\right)$ and highly volatile species (as $\mathrm{HF}$ and $\mathrm{H}_{2} \mathrm{O}$ ).

- Effusion cell and "ion source" housings are well insulated - fitted with a special restricted molecular beam device developed by Chatillon and co-workers [9] - and equipped with large 
pumping capacities, respectively 1300 and $800 \mathrm{l} / \mathrm{s}$ which correspond to 900 and $450 \mathrm{l} / \mathrm{s}$ at the level where the molecules are produced or ionized.

The study of the gas flows in a system of tubings and enclosures linked in series are the principal topic of this study. For that, it is essential to review the key theoretical concepts so that to enable achieving our goals:

- Dimensioning of the device; if one compares with commercial devices [10], their compactness has intermediate adjustments which facilitate the adaptation to any enclosure but they present the disadvantages to be neither reproducible nor to allow quantitative measurements. Thus fixing the device with multiple sections will allow us the possibility to match the various aspects of the calculation theory with an adequate geometry.

- Obtaining a better flow and pressure control in the whole device according to the spectrometric experimental final conditions, with possibility of calibration of the instrument for quantitative measurements, in terms of gaseous flow consumed or produced during mechanical millings.

To make our flow calculations close to the planned experiments, we must explain the relation with the hydrides mechanism commonly called "absorption/desorption". As described in the literature [11,12], HP-DSC measurements coupled to Sievert apparatus - for kinetic study goal - have allowed to observe the reaction of dehydrogenation of $\mathrm{LiBH}_{4}$ or $\mathrm{NaBH}_{4}$ destabilized by $\mathrm{MgH}_{2}$ according to two following stages while heating at $465^{\circ} \mathrm{C}$.

$$
\mathrm{MgH}_{2}(\mathrm{~s})+2 \mathrm{LiBH}_{4}(\mathrm{~s}) \longleftrightarrow \mathrm{Mg}(\mathrm{s})+2 \mathrm{LiBH}_{4}(\mathrm{~s})+\mathrm{H}_{2}(\mathrm{~g}) \longleftrightarrow \mathrm{MgB}_{2}(\mathrm{~s})+2 \mathrm{LiH}(\mathrm{s})+4 \mathrm{H}_{2}(\mathrm{~g})
$$

$\mathrm{X}$-rays diffraction - performed after experiment - showed that this reaction is much more complex by revealing the existence of several other possible phases. These phases are probably formed during the process of reactivation of the powders by milling or when heating at high temperature. The above reaction supposes the appearance of the only hydrogen in the gas phase, whereas at mentioned temperatures other vapor pressures can be also important. Consequently, different species resulting from milling, such as $\mathrm{H}_{2}, \mathrm{~B}_{2} \mathrm{H}_{6}$ (e.g. borohydrides), $\mathrm{H}_{2} \mathrm{O}$ and $\mathrm{HF}$ (in case of fluorinated doping agents) are expected. It is thus necessary to analyze very small gas flow continuously sampled from the milling reactor, meanwhile the milling conditions and parameters can be varied. For an amount of 2.5 $\mathrm{g}$ of $\mathrm{MgH}_{2}$ sample, about 0.095 mole of hydrogen can be released at $300^{\circ} \mathrm{C}(2.1 \mathrm{~L}$ under normal conditions). Knowing that under the present spectrometric conditions the release of hydrogen could be complete in approximately 26 hours, it is important to calculate the real conditions which will enable to optimize this flow in the final effusive stage. The milling reactor is designed to be adjustable in term of pressure and temperature, as well as flow capabilities for different gaseous species. According to the set geometry, it can allow to carry out measurements close to equilibrium in addition to kinetic studies. 
Here, we describe more precisely the architecture of the experimental device, as well as the inlet system to carry out such connection and to ensure precise and reliable measurements. Gas flow determination in each section is based on the appropriate flow equations depending on geometry.

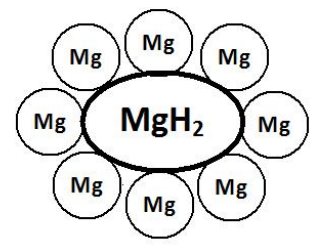

(i)

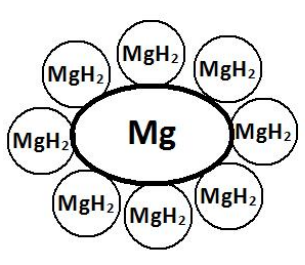

(ii)

Figure 1. Model of rate-limiting steps, during hydrogen (i) desorption and (ii) absorption.

\section{Methodology and preliminary data}

\subsection{Description of the milling reactor, inlet system and connection to the effusion cell}

For gas introduction two systems can be considered: -(i) a capillary tube or -(ii) a micronic nozzle with supersonic beam already used by Chatillon and other recent works [13,14]. The nozzle is used when one wants to avoid vapor condensations in the capillary tubes. A simple capillary tube is the system more convenient for non-condensable gas when not reactive species must be detected. The capillary tube has also the advantage of allowing a certain distance between the milling device and the spectrometer to avoid the transmission of the milling vibrations.

The gas sampling system from the mill to the spectrometer must ensure a very small gas flow in the effusion cell. As the capillary flow is somewhat higher than the usual effusion flow, it is decided to provide the effusion cell with a vacuum pumping to ensure a suitable pressure in the range of $10^{-4}$ to at least $10^{-7}$ bar (knowing that our limit for detection is about $10^{-11}$ bar in the effusion cell). The pressure in the effusion cell produces a molecular beam directed to the ionization chamber (Fig. 2). A mobile shutter located on the way of the molecular beam allows at any moment to distinguish the molecules of the molecular beam coming directly from the effusion cell orifice from those identical existing at steady state in the pumping flow of the ion source. The molecular beam could be also disturbed by phenomena related to physicochemical interactions of the gas species with the different walls. Morland et al.[9] proposed the use of a restricted collimation device to optimize the molecular beam sampling. This type of measurement makes possible to monitor directly the pressure of a permanent gas, contrary to the commercially available assemblies which take into account the residual signal only by interpolating before and after introduction (the so-called "blank") without knowing in fact the evolution of the real background during the measurements. 


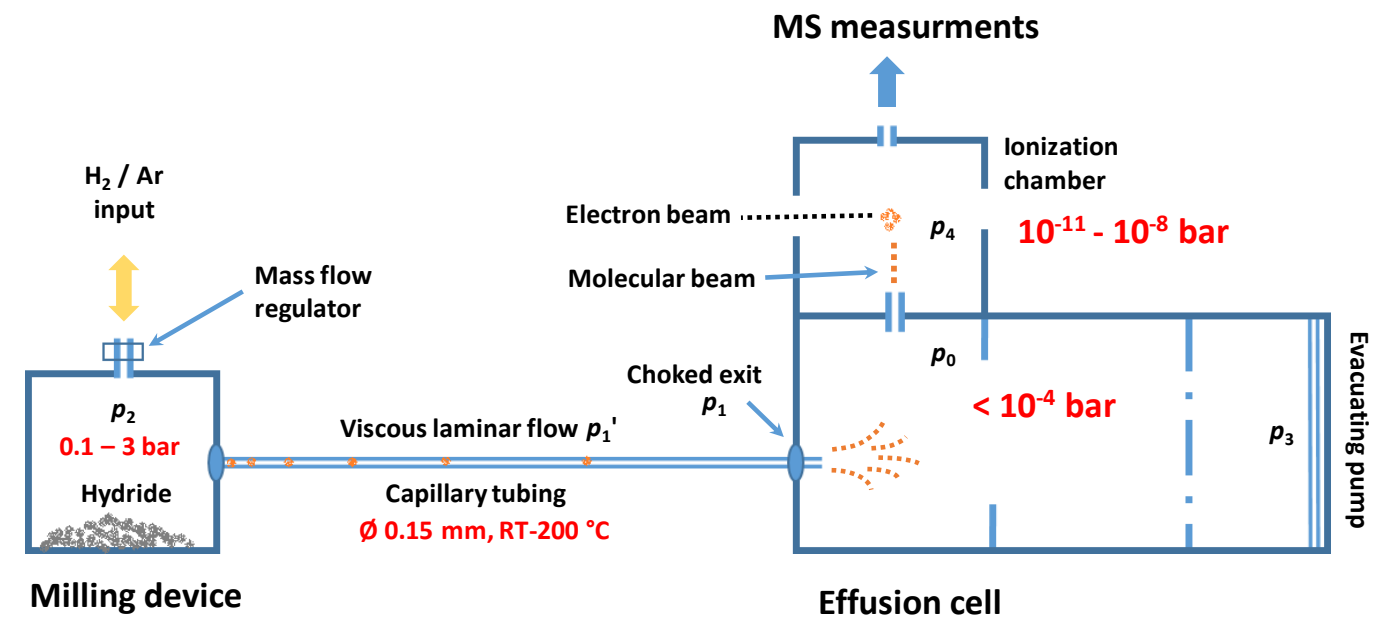

Figure 2. Distribution of the total pressures in the whole experimental device: effusion cell connected to the mill through the capillary tube and the system of regulation of pressure of the effused beam toward the mass spectrometry. Different pressure regions throughout the capillary tubing with a choked exit is also illustrated.

From this analysis and a preliminary calculation, we consider the coupling between the ball-mill and the effusion cell by a long capillary tube $(1-3 \mathrm{~m})$ with a diameter of about 1.5 to $0.15 \mathrm{~mm}$ and an orifice characterized by a choked exit in the effusion cell. The orifice of the effusion cell has the standard size $(2 \times 2 \mathrm{~mm}$ : diameter $\times$ length $)$ used in the present spectrometer with a continuous production of the molecular beam. A primary pump connected directly to the effusion cell is planned to ensure the Knudsen conditions at the cell orifice $\left(p_{0}<10^{-4}\right.$ bar). The whole device will be maintained at temperature higher than $100{ }^{\circ} \mathrm{C}$ to avoid condensation and adsorption phenomena especially for water along the capillary tube. Considering that the experiment requires a continuous contribution of hydrogen in the mill, a flow or pressure controller fitted with a dosing valve will be set up on the input line for the introduction of the gas $\left(\mathrm{H}_{2}+\mathrm{Ar}\right)$. This unit will also allow a calibration of the pressures or flows of gas used as carrier gas. Total pressure measurements will be also monitored in the effusion cell using a Baratron ${ }^{\circledR}$ capacitance gauge. This will help to calibrate the mass spectrometer knowing the total pressure by applying the Knudsen formula displayed below. The ballmill (vibrating type) is made of stainless steel. This material was chosen for non-reactivity with certain number of hydride compounds. The connection to the effusion cell is made using a flexible-tube then followed by a thin capillary-tube. The ball-mill is constituted from five distinct pieces (Fig. 3a): a vial, air tight lid, plate holder, hollow space for hot air circulation and a single ball. 

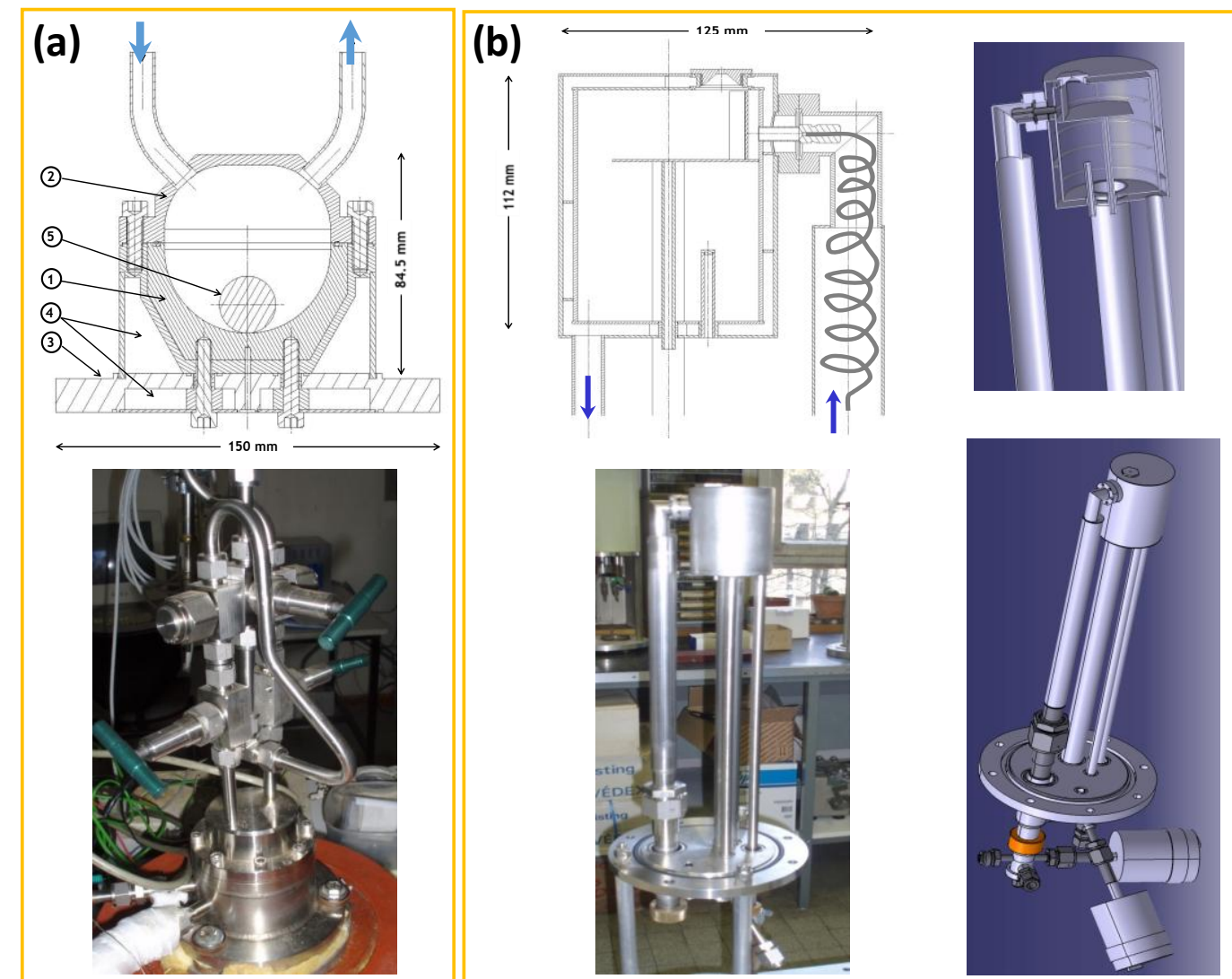

Figure 3. (a) Cross section and photographic image of the ball-milling device. (1) vial; (2) airtight lid fitted with a "Viton ${ }^{\circledR}$ " gasket; (3) plate holder; (4) hollow space for hot air circulation; (5) ball of 20-30 mm diameter. (b) Schema of the cross section of the effusion reactor-cell. The corresponding photographic (below) and 3D (right side) images are also shown.

The inner shape of the vial has a quasi-ellipsoidal cavity wall. The shape allows the getting back of the ball at the right balance during milling. The inner diameter at the top of the vial is $64 \mathrm{~mm}$ with a height at middle of $35 \mathrm{~mm}$. All the parts of the ball-mill are machined from standard stainless steel "304 L", except the main part of the vial has been built from stiffer stainless steel "630 AISI", heat treated at $1050{ }^{\circ} \mathrm{C}$ then re-heated at $480{ }^{\circ} \mathrm{C}$ for hardness increasing. The procedure was made and certified by a supplier who provides a hardness of $44 \mathrm{HRC}$ (1472 MPa) compared to a standard stainless steel which is around $500 \mathrm{MPa}$. As for the other parts, the external part of the vial was made of stainless steel "304 L" without any treatment to ensure a good connection with the plate holder. The airtight lid is attached to the vial by screws. The tightness is ensured by a FPM O-ring (i.d. $2 \mathrm{~mm}$, temperature range $-20^{\circ} \mathrm{C}$ to $+204^{\circ} \mathrm{C}$ ) placed in a groove. Two holes (i.d. $5 \mathrm{~mm}$ ) were drilled in the lid and welded to stainless steel tubes. One of them will be used for pumping or gas flow inlet, while the second is the outlet for gaseous analysis. The vial is fixed to a cylindrical plate $(15 \times 150 \mathrm{~mm})$ by four screws. A hollow space was machined in the plate for air heating system. A circular wall of $2 \mathrm{~mm}$ thickness encloses the vial for air heating with connection to the plate to allow homogeneous heating of the whole mill. The ball is made of a steel material. Different ball sizes (20-30 mm diameter) were tested depending on the 
energy which would be transmitted to the material to be milled. A hole of $3 \mathrm{~mm}$ is drilled in the bottom wall of the mill for K-type thermocouple insertion; hence the temperature could be measured at $5 \mathrm{~mm}$ below the sample.

Gas inlet system supplies dihydrogen, argon and their mixtures. The gas flow can be adjusted in the desired proportions by a system of valves and mass flow controllers. The gas pipes are connected to a primary vacuum pump for evacuation either in the pipes system or in the milling-reactor as it's illustrated in the synoptic schema of the pipes (Fig. S1). The connection from the ball-mill to the effusion cell (Fig. 3b) will be progressively made by flexible-tube of $1 \mathrm{~m}$ length (i.d. $1.5 \mathrm{~mm}$ ) directly welded to the ball-mill aiming to the absorption of the vibrations during milling. The tube is followed by thin capillary-tube $1-3 \mathrm{~m}$ length (i.d. $0.15 \mathrm{~mm}$ ) to ensure gradual decrease of the pressure from atmospheric pressure in the ball-mill to convenient vacuum $\left(<10^{-4}\right.$ bar $)$ in the effusion cell of the mass spectrometer. The connection between the two tubes is made of a Swagelok ${ }^{\circledR}$ screw connector. The capillary is inserted in a heatable larger tube (o.d. $25 \mathrm{~mm})$ after its coiling in spiral form before its connection to the cell by suitable nozzle.

\subsection{Gas flow theory and flow calculations in the input lines}

When a gas flows inside a tube, there are 3 different configurations of flow regimes: molecular, transition and viscous regime. In the case of pressure gradient through a cylindrical tube, the Knudsen number $K_{\mathrm{n}}$, allows the determination of the gas flow regime. It is given by the following formula:

$$
K_{\mathrm{n}}=\frac{d}{\lambda}
$$

where $d$ is the diameter of the exit orifice and $\lambda$ is the mean free path of molecules in the gas, given by the expression:

$$
\lambda=\frac{R T}{\pi \sqrt{2} N_{\mathrm{A}} \sigma^{2} p}
$$

$R$ is the ideal gas constant, $p$ the pressure, $T$ the temperature, $N_{\mathrm{A}}$ the Avogadro number and $\sigma$ the Van Der Waals diameter of the considered molecule [15].

The various gas flow regimes in a tubing are thus defined according to the Knudsen number $K_{\mathrm{n}}$ :

- If $K_{\mathrm{n}} \leq 3$, the flow is molecular, i.e. only the collisions with the walls are taken into account,

- If $K_{\mathrm{n}} \geq 80$, the flow is viscous,

- If $3 \leq K_{\mathrm{n}} \leq 80$, the flow corresponds to the transition regime (intermediate between molecular and viscous).

The viscous regime can be laminar or turbulent. The distinction between these two types of flows can be determined according to the Reynolds number $\left(R_{e}\right)$ : 


$$
R_{e}=\frac{4}{\pi} \cdot\left(\frac{M}{\eta}\right) \cdot\left(\frac{Q}{d}\right)
$$

where $Q$ is the molar flow, $M$ is the molar weight of the considered fluid, $\eta$ its viscosity at the considered pressure and temperature $T$ and $d$ the diameter of the tubing.

- if $R_{e} \geq 2200$, the flow is turbulent ( $Q \geq 1,73 \cdot 10^{3} \cdot\left(\frac{\eta}{M}\right) \cdot d$ in S.I. units)

- if $R_{e} \leq 1200$, the flow is laminar $\left(Q \leq 9,42 \cdot 10^{2} .\left(\frac{\eta}{M}\right) . d\right.$ in S.I. units).

\section{- Viscous laminar regime}

In our case the choice of the pipes and orifices will be made so that the flow regime could not be turbulent. This feature is connected to the maximal flow which will depend on the size of the chosen capillary. According to Santeler [16], a pressure drop is stated in the presence of a system of pumping down to the vacuum - as in our case - and laminar viscous flow is the predominant regime which can be fixed by the type of tubes and its orifices. He considered a static local pressure instead of a total pressure (Fig. 2) for the evaluation of the gas behavior in systems with molecular and viscous flows. This enables the author to avoid taking into account the mean velocity of the gas line in the pressure value and to consider that the pressure depends on the direction of the measurement related to that of the flow. Thus it allows to develop a series of simple equations for the calculation of the pressure drops in the systems with several compartments and through a large range of pressure from atmospheric pressure to ultrahigh vacuum [16]. If the length to the diameter ratio of the tube is sufficiently large, then the viscous-laminar flow is governed by the Hagen-Poiseuille law which is given by the following formula:

$$
Q_{\mathrm{vis}}=K_{\mathrm{vis}}\left(p_{2}^{2}-p_{1}^{2}\right)
$$

where $K_{\text {vis }}=\frac{\pi a^{4}}{16 \eta l R T}$

$Q_{\text {vis }}$ is the molar viscous flow in mol/s, $l$ and $a$ are respectively the length and the radius of the tube, and $\eta$ is the gas viscosity in poiseuille ( $1 \mathrm{Pl}=1 \mathrm{~Pa} . \mathrm{s})$. Note that Eq. 6 is applied between the two pressures $p_{2}$ (ball-mill pressure) et $p_{1}$ (pressure at the capillary exit) corresponding at each ends of the tube and not between the two compartments $p_{2}$ and $p_{0}$ (effusion cell pressure). Thus, the HagenPoiseuille equation applies only for a tube, but not for its orifice.

- Molecular regime

In the case of a molecular effusion regime, where only the collisions with the walls are taken into account through an effusion orifice or a tube, the effused total flow $\left(Q_{\text {mol }}\right)$ is obtained by the HertzKnudsen relation [17] corrected by a factor known as the Clausing coefficient (Eq. 7) which is the 
probability of transmission of the molecules by an orifice of specified form (generally cylindrical) compared to an orifice ideally thin [18].

$$
Q_{m o l}=\frac{s \cdot C \cdot \Delta p}{\sqrt{2 \pi M R T}}
$$

where $s=\pi a^{2}$ is the section of the orifice, $C$ is the Clausing coefficient and $\Delta p$ the difference in pressure between the two sides of the orifice (the two compartments in this regime).

The Clausing coefficient was discussed by Santeler et al.[19] and confronted with more recent work of Cole [20]. By comparing the various published coefficients and their resulting errors (up to $12 \%$ for $l / d$ $=2$ ), we proposed to use the relation where the maximum error is only $0.6 \%$ :

$$
C=\frac{1}{1+\frac{3 l^{\prime}}{8 a}}
$$

where $l^{\prime}=l\left(1+\frac{1}{3+\frac{3 l}{7 a}}\right)$ is the equivalent length of the orifice which depends on $l$ and $a$ respectively the length and the radius of the orifice. Note that in Santeler's calculations, the exit orifice of a tube is the only one which is considered.

\section{- Choked flow from laminar to molecular transition}

This sonic flow state has the role to restrain the passage from viscous laminar flow to molecular flow (i.e. between the capillary end orifice and the effusion cell i.e. lower pressure compartment) without loss of the operating vacuum. Henry [21] defines the conductance of an orifice in thin wall separating two tanks of pressures $p_{0}$ and $p_{1}\left(p_{0}<p_{1}\right)$. He pointed out that gas flow through this orifice undergoes a contraction, then a succession of relaxations and compressions (shock waves). Afterwards, rearrangement of Wantzel-Zeuner formulas (Eq. 9) and of the equation of the mass flow $\mathrm{G}$ of the gas (Eq. 10), he proposed the formula (Eq. 6.11) of isentropic flow which travels through the orifice.

$$
\begin{aligned}
& u_{0}^{2}=\frac{2 \gamma}{\gamma-1} \frac{p_{1}}{\rho_{1}}\left(1-\left(\frac{p_{0}}{p_{1}}\right)^{\frac{\gamma-1}{\gamma}}\right) \\
& G=s u_{0} \rho_{0} \\
& Q=s \cdot p_{1} \cdot\left(\frac{p_{0}}{p_{1}}\right)^{\frac{1}{\gamma}} \sqrt{\frac{2 \gamma}{\gamma-1} \frac{1}{R T M}\left(1-\left(\frac{p_{0}}{p_{1}}\right)^{\frac{\gamma-1}{\gamma}}\right)}
\end{aligned}
$$


where $u_{0}$ and $\rho_{0}$ being respectively the velocity and density of the gas at the pressure $p_{0}$. $\gamma=\frac{C_{p}}{C_{v}}$ is the heat capacities ratio $(5 / 3=1.67$ for a monatomic gas and $7 / 5=1.4$ for a diatomic or polyatomic gas) and $Q$ is the flow in $\mathrm{mol} / \mathrm{s}$.

By considering the flow evolution when $p_{0} / p_{1}$ ratio decreases or pumping rate increases (Fig. 4), a maximum is observed for a critical ratio:

$$
\frac{p_{0}}{p_{1}}=\left(\frac{2}{\gamma+1}\right)^{\frac{\gamma}{\gamma-1}}=r_{c}
$$

The critical ratio $r_{\mathrm{c}}$, defines the condition of sonic flow as the gas velocity at the exit is equal to the local velocity of the sound for the pressure $p_{1}$. In the sequence of pressure values going from the atmosphere (or more) to the vacuum in the system of introduction between the milling device and the spectrometer, it is important to correctly locate this phenomenon by an adequate geometry. Indeed the sonic regime has the following principal advantages:

- limit at least the maximal gas flow by only the diameter of the tube orifice

- ensure the proportionality between pressure and flow and thus to relate directly the flow value to that of the only upstream pressure measurement

- obtain down to the orifice a molecular regime adapted to the effusion cell in a mass spectrometer.

Fig. 4 represents the variation of the output flow of the gas as a function of the $p_{0} / p_{1}$ ratio through a tube. Flow is known as subsonic for pressure ratios close to unity which corresponds to an adiabatic pressure drop. For an optimal flow, the ratio $r_{\mathrm{c}}$ is known as sonic where the velocity of the particles is equal to the local velocity of the sound. Our computed values correspond well to the theoretical curve in the field of the supersonic flow obtained for weak pressure ratios. According to Eqs. 9-11, the sudden flow change is due to a fast reduction in the density compared to a slow increase in velocity [16]. According to the type of the sampling system, the gas velocity through the exit orifice of the capillary towards the downstream vessel (the effusion cell) could not exceed a limiting threshold that corresponds to sonic regime. If the pressure $p_{0}$ decreases under this critical ratio, Eq. 11 is no more applicable (dashed lines inset Fig. 2) because the only force able to push the molecules out of the orifice is then that contained in the gas, and the maximal flow corresponds at the own molecules velocity (cf. Kinetic theory of gases) to escape the exit plan of the orifice toward the ideal vacuum (no molecule of the compartment of pressure $p_{0}$ comes back to shock the molecules leaving the orifice). For all values $p_{0} / p_{1}<r_{\mathrm{c}}$, the flow according to the Eq. (11) has a maximum and constant flow, called critical flow which corresponds to the choked flow, such as:

$$
Q_{\text {critical }}=p_{1} \cdot C_{\text {choc }}
$$

By considering the total pressures, if the difference in pressure between $p_{0}$ et $p_{1}$ is important, the molecules are ejected as "shocked" at the exit of the tube for a ratio $p_{0} / p_{1}<0.53$. According to the geometry of the orifice at the exit, made up of a cylindrical tube emerging freely in a rather large 
volume, this pressure ratio corresponds to a threshold limit after which a pressure decrease $p_{0}$ will not affect any more the value of the exit flow [22,23].

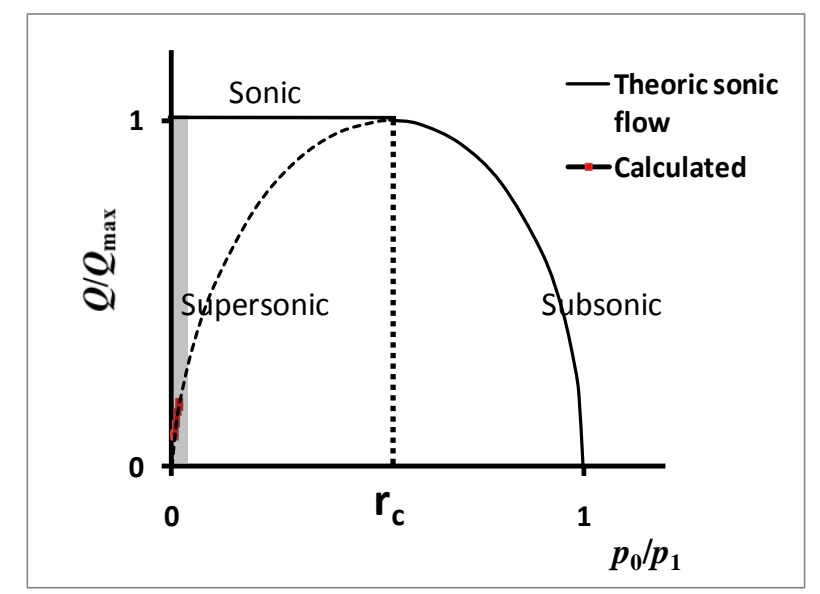

Figure 4. Flow - pressure ratio diagram (sonic flow) according to equation 12 for choked flow during the viscous-molecular transition.

The expression of the conductance $C_{\text {choc }}$ can be simplified to:

$$
C_{\text {choc }}=s \cdot \sqrt{\gamma \cdot\left(\frac{2}{\gamma+1}\right)^{\frac{\gamma+1}{\gamma-1}} \cdot \frac{1}{R T M}}
$$

$C_{\text {choc }}$ depends only on molecule type (its molar mass and monoatomic or polyatomic nature) and on temperature. The flow $Q_{\text {critical }}$ at the orifice remains proportional to the pressure $p_{1}$ before its exit. It is the principle of proportionality which is used in the flow controllers in general. Note that for this choked flow no molecules can come backwards in the tube. The expression of the critical flow $\left(Q_{\text {critical }}\right)$ in the orifice, imposed by the shock effect of the gas particles could be reduced to the Eq. 15 by eliminating the pressure $p_{1}$ in relation (6) by substitution from the Eq. 13. This formula was also included in the work of Santeler [16] for a tube with a choked exit by considering the total pressure:

$$
Q_{\text {critical }}=\frac{C_{\text {choc }}^{2}}{2 K_{\mathrm{vis}}}\left[\sqrt{1+\left(\frac{2 K_{\mathrm{vis}} p_{2}}{C_{\mathrm{choc}}}\right)^{2}}-1\right]
$$

- Transition regime

The transition regime is an intermediate regime between molecular and viscous-laminar and which corresponds to a Knudsen number between 80 and 3. For a compressible flow DeMuth et al.[24] developed a model which combines the expressions of the two other flows, molecular $\left(Q_{m o l}\right)$ and $\operatorname{viscous}\left(Q_{v i s}\right)$. They use the Knudsen number $\left(K_{n}\right)$ to combine these flows, in particular for values between 2 and 45 according to the expression: 


$$
Q_{\text {trans }}=Q_{\text {vis }}\left(1-C a^{-K \mathrm{n}}\right)+Q_{\mathrm{mol}} C a^{-K \mathrm{n}}
$$

The experimental constant of DeMuth $C a=1.05$, represents the inverse of the probability that a molecule after collision with another molecule will not be hit against the walls of the orifice. The use of the Knudsen number in this relation has a physical significance where the molecular percentage of flow represents the number of molecules able to go upward the tube after collisions (molecular regime) on the walls. The remaining percentage is the contribution of viscous flow. This model considers an asymptotic regression of the molecular regime towards an isentropic regime, generally viscous-laminar, where the pressure ratio is maintained constant.

\subsection{Computing the different flow modes}

In order to quantify the flows in the whole device, from the mill to the mass spectrometer calculations were carried out using VBA language under Excel Macros. The final program is given in the Appendix (Suppl. Info.). All the units are in S.I. unit and flows $Q$ are in molar flow (mol/s).

The viscosity (in $\mathrm{Pl}$ ) of dihydrogen was obtained starting from a polynomial regression of $\eta=\mathrm{F}(T)$ from the data of the CRC [18]:

$$
\eta_{\mathrm{H}_{2}}=-1.0893 \cdot 10^{-11} \times T^{2}+2.7796 \cdot 10^{-8} \times T+1.59 \cdot 10^{-6}
$$

Note, the choke constant $C_{\text {choc }}$ (Eq. 14) depends on the nature of gas by its mass. This will be calculated for each type of gas. The shock becomes limiting when the ratio satisfies $p_{0} / p_{1}<r_{\mathrm{c}}$. This latter case is set as criterion where the pressure $p_{0}$ (effusion cell) can be always much lower than $p_{1}$. Due to the complexity of the calculation, Santeler [16] proposed a practical method to solve systems with multi-elements inter-connected between them. He supposed that each tube and its exit are calculated as two different elements which allows to define a flow regime at each stage. For example, the tube could work in laminar flow and its exit in "shocked" regime if the downward pressure corresponds to the molecular vacuum, which is the case for a capillary connected to a pumped effusion cell in this study.

The strategy of calculation consists in choosing a section of the system with an imposed pressure at the entry. The flow will be calculated starting from the pipes dimensions. Then each section will be solved by iteration in order to obtain the pressure at the entry of the following section. A simplified schema is given in Fig. 5 illustrating the reasoning sequences.

In the suggested equation, three principal flows will be distinguished: the viscous flow in the capillary $Q_{\text {vis }}$, the pumping flow $Q_{\text {pump }}$ that is connected to the effusion cell and the effusion flow $Q_{\text {eff }}$ (towards the spectrometer). At the effusion cell level, the flows are described by the flow steady-state balance:

$$
Q_{\text {eff }}=Q_{\text {vis }}-Q_{\text {pump }}
$$


The computational solution is based on the sign change of the relation $Q_{\text {pump }}-Q_{\text {vis }}+Q_{\text {eff }}$.

Because the choice of primary pump is imposed by the offer of different suppliers, this condition must be the beginning of iteration calculation first without taking into account the effusion flow. For that we have proceeded by dealing with each section apart as presented below.

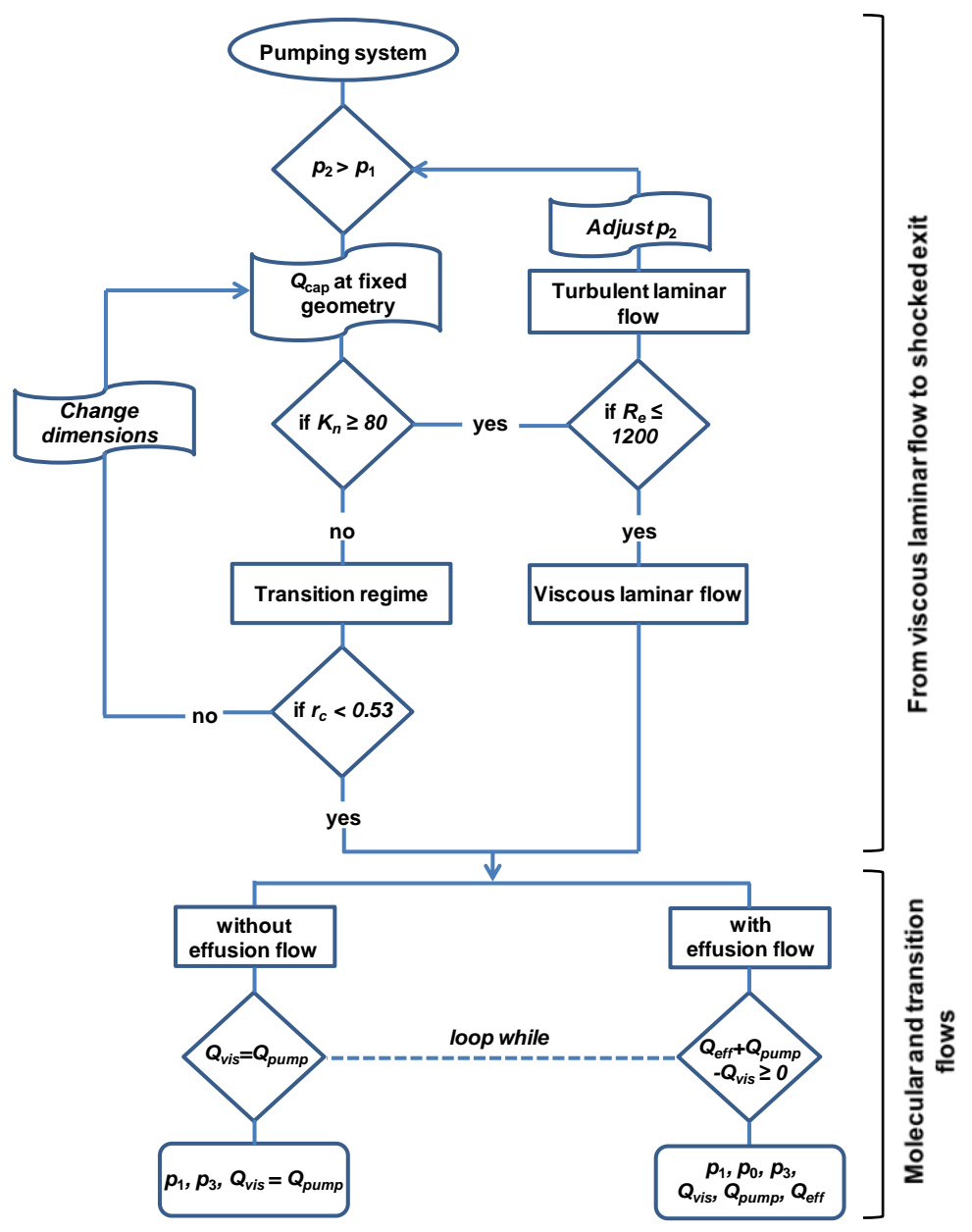

Figure 5. Simplified algorithm used for the solving of the flow equations

\subsubsection{Connection between the ball-mill and the capillary}

The total pressure $p_{2}$ in the ball-mill, is also the pressure at the entrance of the capillary. Two flows are expected; viscous-laminar flow in the capillary tube, followed by the choked flow at the exit, both being connected by $p_{1}$ (Fig. 2) which will be the parameter of calculation in order to equalize the two flows.

Knowing that the pressure $p_{1}$ should be lower than $p_{2}$ (and higher than $p_{0}$ which is very small), we define $p_{1}=p_{2} /$ step, where the step in the interval $\left[p_{2} ; p_{0}\right]$ is such as: step $=\left(p_{2}-p_{0}\right) / 10$. In the program, a loop determines the value of $p_{1}$ using the flow equations in particular the Hagen-Poiseuille relation (Eq. 6) and the choked flow formula (Eq. 15). By solving the following flows equality: 


$$
Q_{\text {vis }}-Q_{\text {critical }}=\mathrm{f}\left(p_{1}\right)=0
$$

We deduce a direct expression for the calculation of $p_{1}$ which depends only on the pressure $p_{2}$ for a given gas species and temperature:

$$
p_{1}=\frac{C_{\text {choc }}}{2 K_{\text {vis }}}\left[\sqrt{1+\left(\frac{2 K_{\text {vis }} p_{2}}{C_{\text {choc }}}\right)^{2}}-1\right]
$$

The mill and the capillary are not linked in a direct way but by an intermediate tube which will be used as vibrations absorber of the movements of the mill. This quite large (i.d. $1.5 \mathrm{~mm}$; length $1 \mathrm{~m}$ ) tubing has been checked to have no effect on the calculations results (negligible pressure gradient).

\begin{tabular}{|c|c|c|c|c|c|}
\hline$p_{2}$ (mbar) & $p_{1}$ (mbar) & $Q_{\text {cap }}\left(\mathrm{mol} \cdot \mathrm{s}^{-1}\right)$ & $D(\mathrm{Sccm})$ & $t_{\text {residence }}(\mathrm{s})$ & $\mathrm{Kn}_{\text {cap }}$ \\
\hline 10000 & 113,2 & $5,162.10^{-5}$ & 10,89 & 0,10 & $\overline{3322,6}$ \\
\hline 7943 & 71,40 & $3,257.10^{-5}$ & 8,65 & 0,12 & 2633,2 \\
\hline 5012 & 28,43 & $1,297.10^{-5}$ & 5,46 & 0,19 & 1656,0 \\
\hline 3981 & 17,94 & $8,182.10^{-6}$ & 4,34 & 0,24 & 1313,9 \\
\hline 2512 & 7,141 & $3,257.10^{-6}$ & 2,74 & 0,39 & 827,6 \\
\hline 1995 & 4,506 & $2,055.10^{-6}$ & 2,17 & 0,49 & 657,0 \\
\hline 1585 & 2,843 & $1,297.10^{-6}$ & 1,73 & 0,61 & 521,6 \\
\hline 1259 & 1,794 & $8,182 \cdot 10^{-7}$ & 1,37 & 0,77 & 414,2 \\
\hline 1000 & 1,132 & $5,163.10^{-7}$ & 1,09 & 0,97 & 328,9 \\
\hline 794 & 0,714 & $3,257.10^{-7}$ & 0,87 & 1,23 & 261,2 \\
\hline 631 & 0,450 & $2,055.10^{-7}$ & 0,69 & 1,54 & 207,4 \\
\hline 501 & 0,284 & $1,297.10^{-7}$ & 0,55 & 1,94 & 164,8 \\
\hline 398 & 0,179 & $8,182.10^{-8}$ & 0,43 & 2,44 & 130,9 \\
\hline 316 & 0,113 & $5,163 \cdot 10^{-8}$ & 0,34 & 3,08 & 103,9 \\
\hline 251 & 0,071 & $3,257.10^{-8}$ & 0,27 & 3,87 & 82,6 \\
\hline 200 & 0,045 & $2,055.10^{-8}$ & 0,22 & 4,88 & 65,6 \\
\hline 100 & 0,011 & $5,163.10^{-9}$ & 0,11 & 9,73 & 32,9 \\
\hline
\end{tabular}

Table 1. Flow calculation in the section: mill - effusion cell

The first calculated results (Table 1) show that in our case, the flow in the capillary will be always higher than the maximum effusion flow $\left(2.43 \cdot 10^{-6} \mathrm{~mol} / \mathrm{s}\right.$ obtained for an effusion maximum pressure of $10^{-4}$ bar) as soon as the upward pressure exceeds 2 bar. But assuming the optimal conditions for measurements with the effusion cell, $p_{0}$ will lie between $10^{-5}$ and $10^{-6}$ bar. The effusion flow shall then then not exceed $2.43 \cdot 10^{-7} \mathrm{~mol} / \mathrm{s}$. In this case, the upward pressure in the mill should not be lower than 400 mbar so that the condition of choked flow could be maintained. However, connecting an additional pump to the effusion cell part is necessary for the evacuation of the excess flow arriving from the capillary when the upstream pressure is larger than 400 mbar. This result seems to be less satisfying when the upstream pressure is lower than 250 mbar, because the flow regime in the capillary 
moves from viscous to transition and the residence time becomes higher. This feature can distort our mass spectrometric analysis of the vapor phase when containing reactive species because interactions with the capillary can take place. On one hand, this is dependent on the affinity of the constituents of the vapor phase with respect to the capillary. Moreover, certain molecules can have short life times as it is the case for the boron hydrides $\mathrm{B}_{\mathrm{n}} \mathrm{H}_{\mathrm{m}}$ species. The problem can be avoided while working with upstream pressures higher than the mentioned thresholds. Excess flow introduced in the effusion cell must be evacuated by a primary pump.

\subsubsection{Flow balance between the capillary and the effusion cell with additional pumping}

In order to choose the suitable characteristics of the primary pump the first approach is to look for the pumping of the total flow resulting from the capillary without taking into account the effusion flow. Thus the flow entering the effusion cell - depending only on the capillary upstream pressure $p_{2}$ - must be entirely evacuated by the primary pump connected to the effusion cell. The pressure $p_{3}$ at the pump entry and the effusion cell pressure $p_{0}$ will depend on the capacity of the pump (volumetric flow as expressed according to $p_{3}$ ). From the pump data provided by the manufacturer (Alcatel $2015 \mathrm{SD}$ ), a fit was performed giving the volume flow versus the inward pressure of the pump (Fig. S2): $D$ in $\mathrm{m}^{3} / \mathrm{h}=\mathrm{f}$ $\left(p_{3} / \mathrm{Pa}\right)$. Three areas are fitted as following for which the maximum deviation is $12 \%$ from the pump flow characteristics:

$$
\begin{array}{ll}
\text { if } p_{3}>1 \quad & ; D=1.4191 \times \log \left(p_{3}\right)+6.3424 \\
\text { if } p_{3} \leq(1.7838 / 7027) & ; D=0 \\
\text { else } \quad ; D=7.027 \times p_{3}-1.7838
\end{array}
$$

A scanning of the pressure $p_{3}$ (from $10^{2}$ to $10^{-2} \mathrm{~Pa}$ with a step in power of -0.001) allows to determine the flow $D$ or flow $Q_{\text {pump }}$ (Eq. 21 and Eq. 22) and the steady state pressure $p_{0}$ in the effusion cell (Eq. 23). The conductance between the effusion cell and the pump depends on the fixed geometry and on the $p_{3}$ value. The calculation is performed for molecular and transition regimes. In the latter case, the problem is solved by iteration using the formula developed by DeMuth (Eq. 16). The flow regime in the effusion cell-pump entry section is at each time determined by the Knudsen number $K_{\mathrm{n}}$.

$$
\begin{aligned}
& Q_{\text {pump }}=D \cdot p_{3} /(3600 R T) \\
& p_{0}=p_{3}+\frac{Q_{\text {pump }}}{C_{\text {cell }}}
\end{aligned}
$$


$C_{\text {cell }}$ is the cell conductance related to its pumping tube deduced starting from the Eq. 7 for a molecular regime, such as:

$$
C_{\text {cell }}=\frac{s C}{\sqrt{2 \pi M R T}}
$$

Now it is possible to find the suitable $p_{3}$ (and the corresponding pressure $p_{0}$ ) which corresponds to the capillary flow for an imposed $p_{2}$. To calculate the steady-state pressures $p_{3}$ (pump entry) and $p_{0}$ (effusion cell) as a function of the upward constant pressure $p_{2}$, we solved for each value of a variable pressure $p_{3}$ the equality of flows between the capillary and the pump entry (loop with precision criterion). Various pressures $p_{2}$ will be considered in a second loop. The results are presented in Fig. 6, showing that the flow resulting from the capillary is directly evacuated by the primary pump. The indicated molecular and viscous flows parts are deduced from transition flow equation. For a pressure upstream of 1.6 bar, the Knudsen number in the cell takes the value 2.8, corresponding to the beginning of the change of the flow regime (molecular to transition). The flow curve obtained is in agreement with the model suggested by DeMuth, i.e. a quasi-asymptotic transition flow to both molecular and viscous regimes.

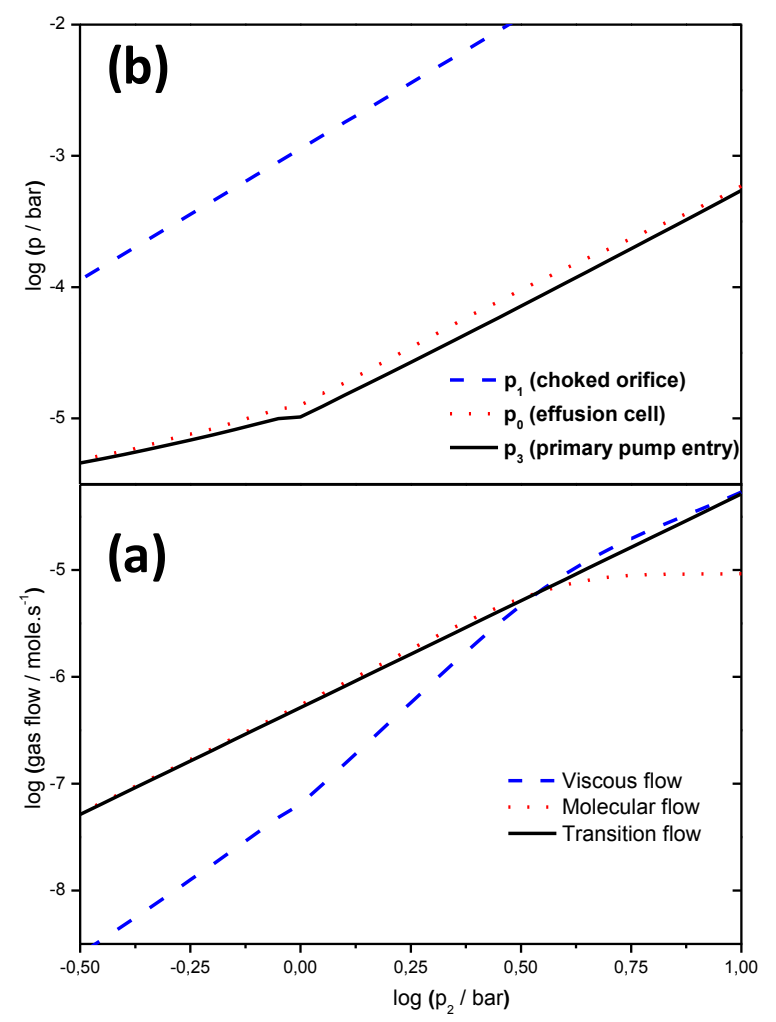

Figure 6. (a) Gas flow regimes in the effusion cell pumping line, and (b) the various pressures in the effusion cell at the pump entry as a function of the upstream pressure $p_{2}$ at the capillary entrance (without taking into account the effusion flow in the flow balance)

In the present case, the acceptable maximal upstream pressure $p_{2}$ is approximately 3 bars, and is limited by the maximum pressure allowed in the effusion cell. This limit is directly dependent on the 
choice of the primary pump and its connection line to the cell. The pressure $p_{1}$ remains 10 times higher than the pressure $p_{0}$, and the exit of the capillary remains choked. By comparing the two pressures $p_{0}$ and $p_{3}$, the difference between these two pressures reflects an adaptable functioning of the additional pump upon the pressure $p_{2}$. Note, the slope changing is due to the pumping mode (Fig. S2): from quasi-linear mode to logarithmic mode. At this point, it was also observed the most important relative error.

In this part, we have considered a line of direct flow (from the capillary to the pump evacuation) without taking into account the effusion flow towards the mass spectrometer. Doing so it enables us to choose the capacity of the primary pump for low and high upstream pressures ( $p_{2}$ from 100 mbar to 10 bar). At high pressure, we noted that its role is to evacuate the main part of the flow. Note that the flow in the capillary becomes of transition type below an upstream pressure equal to 250 mbar. For the next section where the effusion flow is introduced in the set of equations, the pressure range of $p_{2}$ will be varied between 3000 and 250 mbar.

\subsubsection{Flow optimization throughout the effusion cell}

The real working of the entire flow-lines must take account of all the flows: capillary, effusion cell and pump. The evaluation of the optimal pressure $p_{3}$ and the pressure $p_{0}$ (effusion cell) will be made starting from the steady state of the flow i.e. the relation: $Q_{\text {eff }}=Q_{\text {vis }}-Q_{\text {pump }}$. The test was carried out using various loops to determine the pressure $p_{3}$ corresponding to each value of $p_{2}$, and based on the inequality: $Q_{\text {pump }}+Q_{\text {eff }}-Q_{\text {vis }} \geq 0$, which means that the pump must evacuate at least the excess flow injected by the capillary to the effusion cell. It is also a condition to avoid condensation phenomena on the walls of the cell such as water vapor.

Moreover, for taking into account the transition flow which can occur indeed at the level of the connection tube between the cell and the primary pump entry, the equation of the transition regime is used. The calculation of the pressure $p_{0}$ cannot be done any more simply as in the preceding part because the relation between these two pressures is more complex. Initially we calculated for each imposed pressure $p_{3}$ two values $p_{0}$ min and $p_{0}$ max respectively from the only molecular flow and the only viscous flow equations. By varying $p_{0}$ between these two limits, one can find the exact flow at the pump entry. Thus $Q_{\text {trans }}$ (transition flow) is used to compute the flow in the tube section between the effusion cell and the pump. Results also show that the molecular flow regime enters in the transition regime in the pumping line for an upstream pressure $p_{2}$ above 2 bar (Fig. 7). On the other hand, below 350 mbar, the pumped flow becomes very weak. 


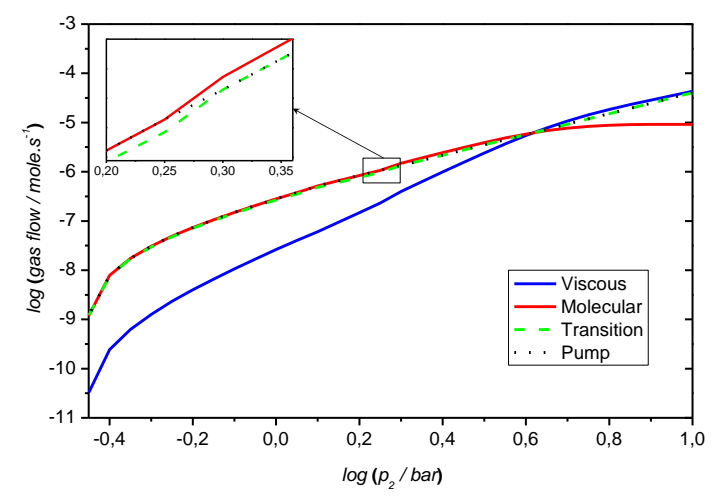

Figure 7. Variation of the flow regimes in the effusion cell-pump line as a function of the pressure $p_{2}$.

The intersection of flows represents equal contributions of viscous and molecular flows in the transition flow equation at the Knudsen number equal 14. At the pressure $p_{2}$ of 1.9 bar, we observe the beginning of the transition flow. Below this pressure, a slight deviation is observed between the transition flow and the real pump flow. This is probably due to the application of the DeMuth model for Knudsen numbers between 3 to 80 (as cited in the literature) instead of 2 to 45 in the case of the DeMuth model determinations. As the contributions of viscous and molecular flows are always appearing in the transition flow relation, the latter can be applied for the full pressure range.

\section{Results and discussion}

\subsection{Choice of the capillary tubing}

The program provides a set of output data that we have used in this paragraph to build the experimental device. In the case of hydrogen gas, it can be noted that an increase of the capillary length (from 1 to $3 \mathrm{~m}$ ) makes it possible to work with low pressures $p_{0}$ in the effusion cell and high upstream pressures $p_{2}$ up to 4 bar. Regarding the diameter of the capillary, the calculation shows that as small as possible diameter is needed. The commercially distributed capillary $0.15 \mathrm{~mm}$ inner diameter fulfils satisfactorily the requirements fixed for our system of introduction. In our case, the input pressure $p_{2}$ could vary from 0.1 to 2.5 bar for ideal working conditions of both the milling device and the spectrometric measurement.

The capillary flow, in the case of $\mathrm{N}_{2}$ gas, is equal to $3 \mathrm{Sccm}$ (Standard cubic centimeters per minute) for an upstream pressure of 2.5 bar with vacuum downstream. By using air, the manufacturer had given an indicative value 2 to $3 \mathrm{Sccm}$ for 1 bar upstream and vacuum downstream. In the case of $\mathrm{H}_{2}$, this same volume flow is already reached with an upstream pressure of approximately 1 bar. The apparent "fluidity" of $\mathrm{H}_{2}$ is due to its low viscosity compared to $\mathrm{N}_{2}$ which suggests working with low upstream pressures in our experiments where the main gas is $\mathrm{H}_{2}$. In the followings the presented results are for the case of hydrogen gas. For an adiabatic flow at the capillary orifice exit, the gas 
escape velocity is limited by the local sound velocity. At this stage, the pressures $p_{1} / p_{0}$ ratio should be maintained lower than the critical ratio $\left(r_{c}\right)$ in order to avoid the transition regime and adiabatic expansion. Besides, the choked exit for the gas can be established only if the pressure $p_{1}$ is in the viscous regime as attested by the Knudsen number.

Fig. 8a shows the flow regime along the capillary represented by the variation of the Knudsen number before the choked exit for various upstream pressures. For the last millimeters before the capillary exit, the gas undergoes a very fast expansion which could affect the isentropic viscous regime at the exit. This regime change becomes more noticeable below 0.5 bar. This is in agreement with our estimations of the choked exit based on the calculation of the critical ratio.
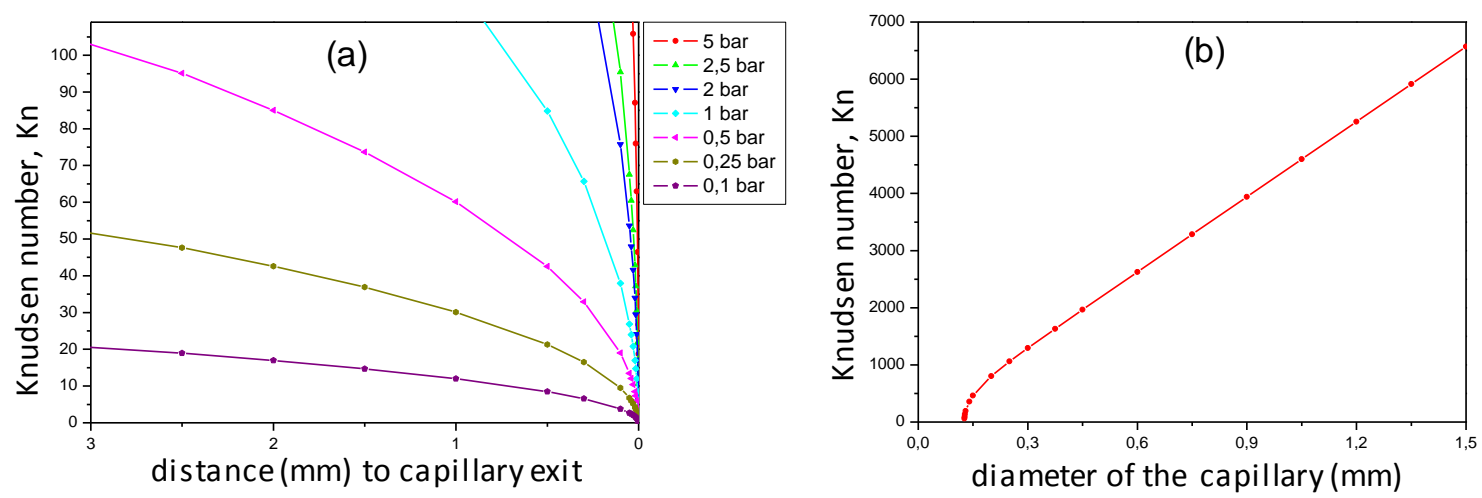

Figure 8. Variation of the Knudsen number upon: (a) the pressure along the capillary, (b) the diameter of the capillary for an upstream pressure of 1 bar

As shown in Fig. 8b, a capillary of small size is more convenient for this study in order to avoid a viscous flow of turbulent type. Although the flow regime in the capillary is in general viscous-laminar, where the pressure $p_{2}$ is lower than 250 mbar, the transition regime occurs at the exit, corresponding to a pressure $p_{1}$ equal to 0.07 mbar. This limit will be that of the lowest pressure $p_{1}$ corresponding to the validity of our calculations. This $p_{1}$ pressure low limit, will give lowest $p_{2}$ limit. Below this pressure limit, the capillary is working, but measurements will not be related to calculation. According to these calculations, it appears that even for low upstream pressures the effusion flow is always negligible compared to the flow issued from the capillary for an upstream pressure lower than 400 mbar. Below this value near 320 mbar, the pump reaches its pumping limits because the pumping flow tends to zero value. In that case, the pump may contaminate the effusion cell with backward flows.

We confirm our assumption that the use of an additional pump is essential in addition to the effusion flow. The pressure in the effusion cell, measurable by the mass spectrometer, will depend on the flow steady state. To be able to regulate this pressure for better optimizing the measurement conditions (increase the Knudsen cell pressure up to $\approx 10^{-5}$ bar) it is necessary to associate a valve with adjustable conductance to the pumping line. 


\subsection{Flows control in the effusion cell with a pumping system}

Fig. 9 presents the variation of the logarithm of the different pressures as a function of the upstream pressure $p_{2}$. It highlights the variation of the difference between the two pressures $p_{0}$ and $p_{3}$ in particular for values of upstream pressures increasingly high. The same situation is observed in the case of a device without effusion flow (Fig. 6). This fact is due to the increase of the pumped flow due to the increase of the pressure gradient (Table 2) between the effusion cell and the primary pump.

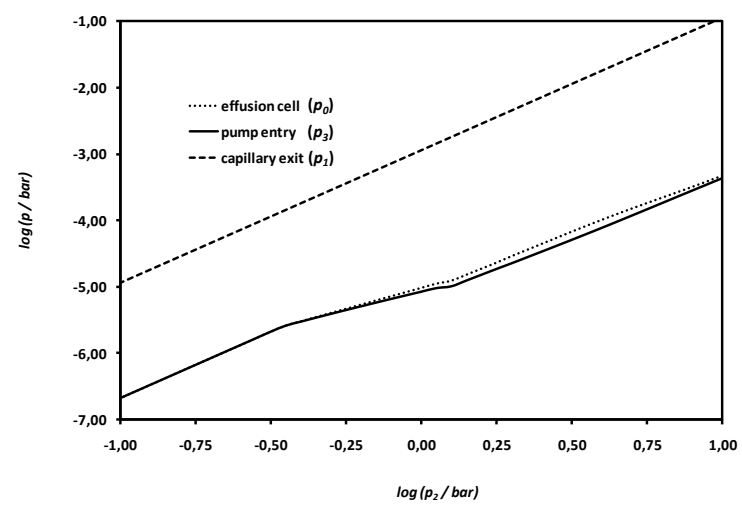

Figure 9. Variation of the different pressures as a function of the upstream pressure $p_{2}$

Table 2. Pressure gradient between the cell and the pump

\begin{tabular}{cccc}
\hline$p_{2}$ (upstream)/ bar & $p_{0}$ (cell)/ bar & $p_{3}(\mathrm{pump}) /$ bar & $\Delta p /$ bar \\
\hline 10,00 & $4,7410^{-4}$ & $4,3410^{-4}$ & $3,9710^{-5}$ \\
8,91 & $3,9010^{-4}$ & $3,5110^{-4}$ & $3,9710^{-5}$ \\
7,08 & $2,6710^{-4}$ & $2,2810^{-4}$ & $3,9110^{-5}$ \\
5,62 & $1,8410^{-4}$ & $1,4810^{-4}$ & $3,6110^{-5}$ \\
5,01 & $1,5210^{-4}$ & $1,1910^{-4}$ & $3,3110^{-5}$ \\
3,98 & $1,0310^{-4}$ & $7,7710^{-5}$ & $2,5110^{-5}$ \\
3,16 & $6,8110^{-5}$ & $5,1310^{-5}$ & $1,6910^{-5}$ \\
2,51 & $4,4610^{-5}$ & $3,4110^{-5}$ & $1,0510^{-5}$ \\
2,00 & $2,9110^{-5}$ & $2,2710^{-5}$ & $6,4010^{-6}$ \\
1,58 & $1,8910^{-5}$ & $1,5310^{-5}$ & $3,6110^{-6}$ \\
1,00 & $9,7010^{-6}$ & $8,4910^{-6}$ & $1,2110^{-6}$ \\
0,71 & $6,2810^{-6}$ & $5,8210^{-6}$ & $4,5710^{-7}$ \\
0,50 & $4,0710^{-6}$ & $3,9410^{-6}$ & $1,3210^{-7}$ \\
0,40 & $3,0410^{-6}$ & $3,0110^{-6}$ & $3,3910^{-8}$ \\
\hline
\end{tabular}


This graph confirms also that the pressure ratio $p_{0} / p_{1}$ is very small in the overall range of the upstream pressures planned for our study (0.1-10 bar). This feature is in agreement with the required conditions of choked flow at the capillary exit. Consequently, the molecular flow criterion in the effusion cell is ensured. As the gas flow in the molecular regime is characterized by independent flows of opposite directions [19], the partial pressures could be influenced by the presence of sources of gas in various places of the gas line. Consequently, the pump can have selective pumping effects for certain gases. To minimize these effects of back flow which could contain impurities, the use of a trap with liquid nitrogen before the primary pump will allow to improve the vacuum and to avoid any undesirable condensations in the effusion cell.

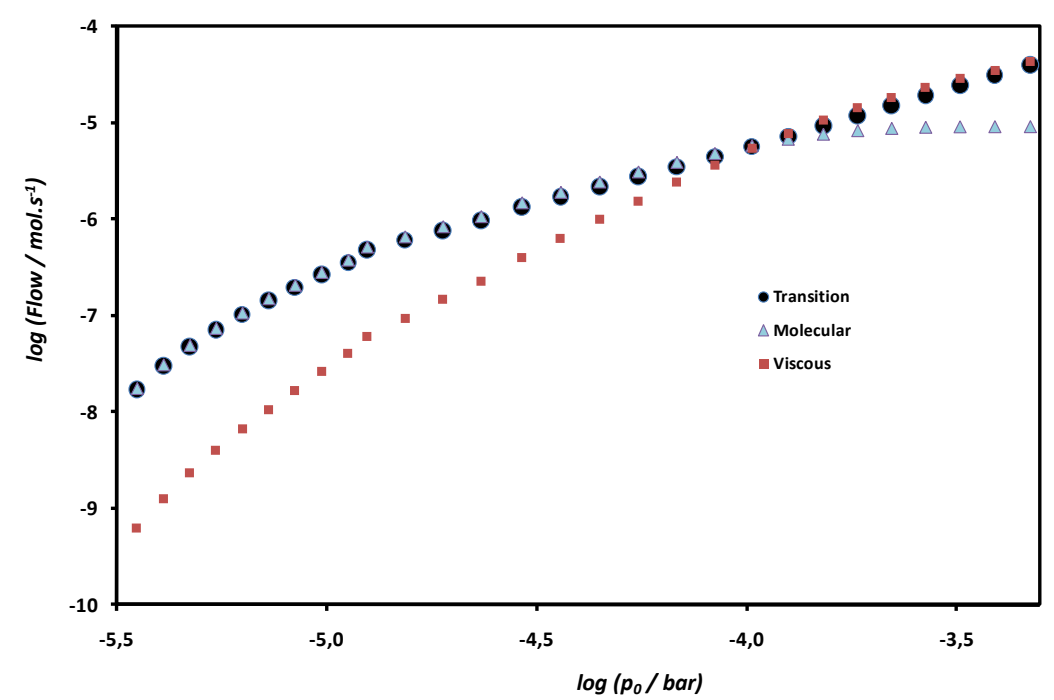

Figure 10. Variation of the transition flow and its viscous and molecular components between the effusion cell and pump entry according to the upstream pressure $p_{0}$ in the effusion cell.

Comparing the various existing regimes as a function of the pressure in the pumping line between the effusion cell and the pump (Fig. 10) using the transition flow formula, we observe that the flow enters in the transition regime just before the pressure approaches the limit of operation of the effusion cell $(\approx$ $10^{-4}$ bar). By analyzing the obtained flow values, we note that the contribution of viscous flow in the pumping tube becomes negligible for upstream pressures $p_{2}$ lower than 1 bar which involves a pressure $p_{0}$ of about $10^{-5}$ bar. Fig. 11 shows the distribution of various flows in the "effusion cell" compartment upon the upstream pressure $p_{2}$ as well as the flow evacuated by the pump. It is to be noted that for upstream pressures lower than 0.4 bar the evacuated flow by the pump becomes negligible. The pump reaches its pumping capacity limit at the corresponding pressure limit. At very low upstream pressures, flow resulting from the capillary is completely evacuated by the effusive flow. For these conditions, the valve of the pump shall be maintained close to avoid any contaminations. 
Taking into account the transition flow equation in the pumping line section brings a significant correction to the pump pressure and consequently to the effusion cell flow in particular for upstream pressures higher than 2 bar. The transition regime seems to occur also at the capillary exit (the few last centimeters) for upstream pressures $p_{2}$ lower than 0.5 bar. Calculation of the Knudsen number for various upstream pressures and according to the distance along the capillary, shows that the transition flow could not be avoided. The choked flow at the exit of the capillary remains, however, available because the viscous contribution is important and the ratio $p_{0} / p_{1}$ is very small. The transition flow becomes more pronounced for low upstream pressures. A molecular flow is also established in the capillary (near the exit) for upstream pressures lower than 100 mbar. The higher limit of the pressure $p_{2}$ is approximately 4 bar, which corresponds to a pressure $p_{0}$ near the threshold pressure in the effusion cell when pumping. For ideal working conditions based on transition flow between the cell and the pump entry, we suggest to work at upstream pressures lower than 2.5 bar.

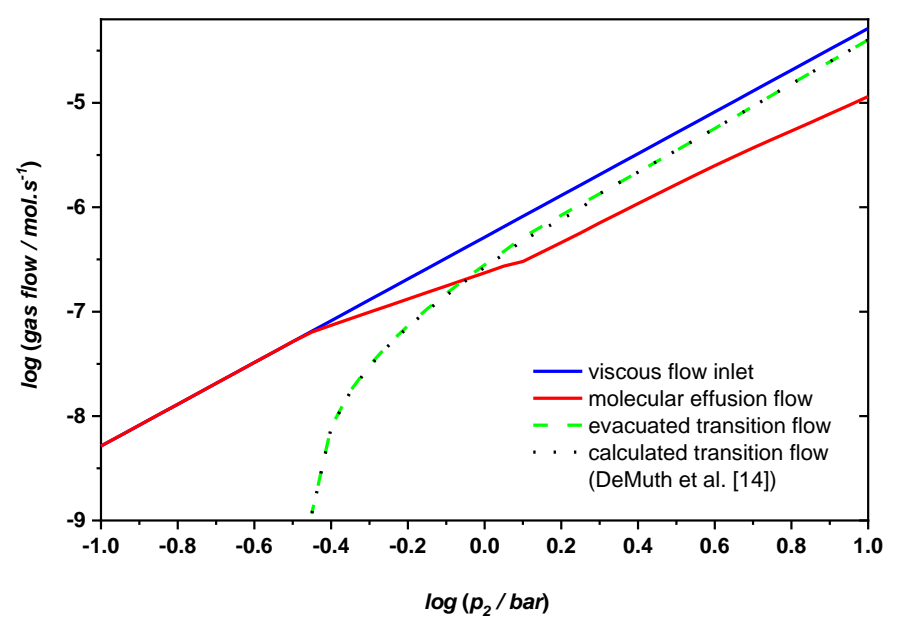

Figure 11. Relationship between different flows for an optimal mass spectrometric operating conditions.

\subsection{Construction of the reactor to be coupled to mass spectrometer}

As the effusion cell assembly is expected to contain only gaseous species issued from the capillary tube, therefore its conception is simplified and consisted on a cylindrical chamber ( $h=68 \mathrm{~mm}, d=30$ $\mathrm{mm}$ ) with a screwed lid fitted with an orifice (i.d. $2 \mathrm{~mm}$ ). The cell device is made of two parts: the main effusion cell and its pumping system (Fig. 12). Details on the cross section of the cell is given in Fig. S3. It will be also useful to measure the total pressure in the effusion cell in order to regulate the flow and calibrate the mass spectrometer. The upstream pressure of the capillary will be fixed using a flow controller with variable pressures in the range $0.1-2.5$ bar. As determined in the flow calculation part, the excess flow is evacuated by the additional pump while only small amounts of the flow effuse toward the ionization chamber for its analysis by the mass spectrometer. The arriving flow from the 
capillary with choked exit is deflected by two walls for allowing a scattered distribution of the flow across the cell compartment (Fig. S3b). The evacuation exit of the cell has the same surface section as for the pumping tube ( $\varnothing 25 \mathrm{~mm}$ ). The measurement of the temperature is performed directly in the cell at two levels by means of two K-type thermocouples, while the pressure measurement in the cell is made by a Baratron ${ }^{\circledR}$ capacitance gauge through a long tube $(10 \mathrm{~mm}$ i.d.). The cell is surrounded by an envelope for air heating circulation to obtain isothermal conditions (Fig. S3a). Baffles were welded alternatively in the air heating compartment to allow the transmission of heat by convection. All parts of the cell made of stainless steel, are welded and tested for air leaks. The cell is mounted on a vacuum flange for its set up and connection to the spectrometer housing. Fig. 12 shows the final architecture of the coupling of the milling device with the mass spectrometer.

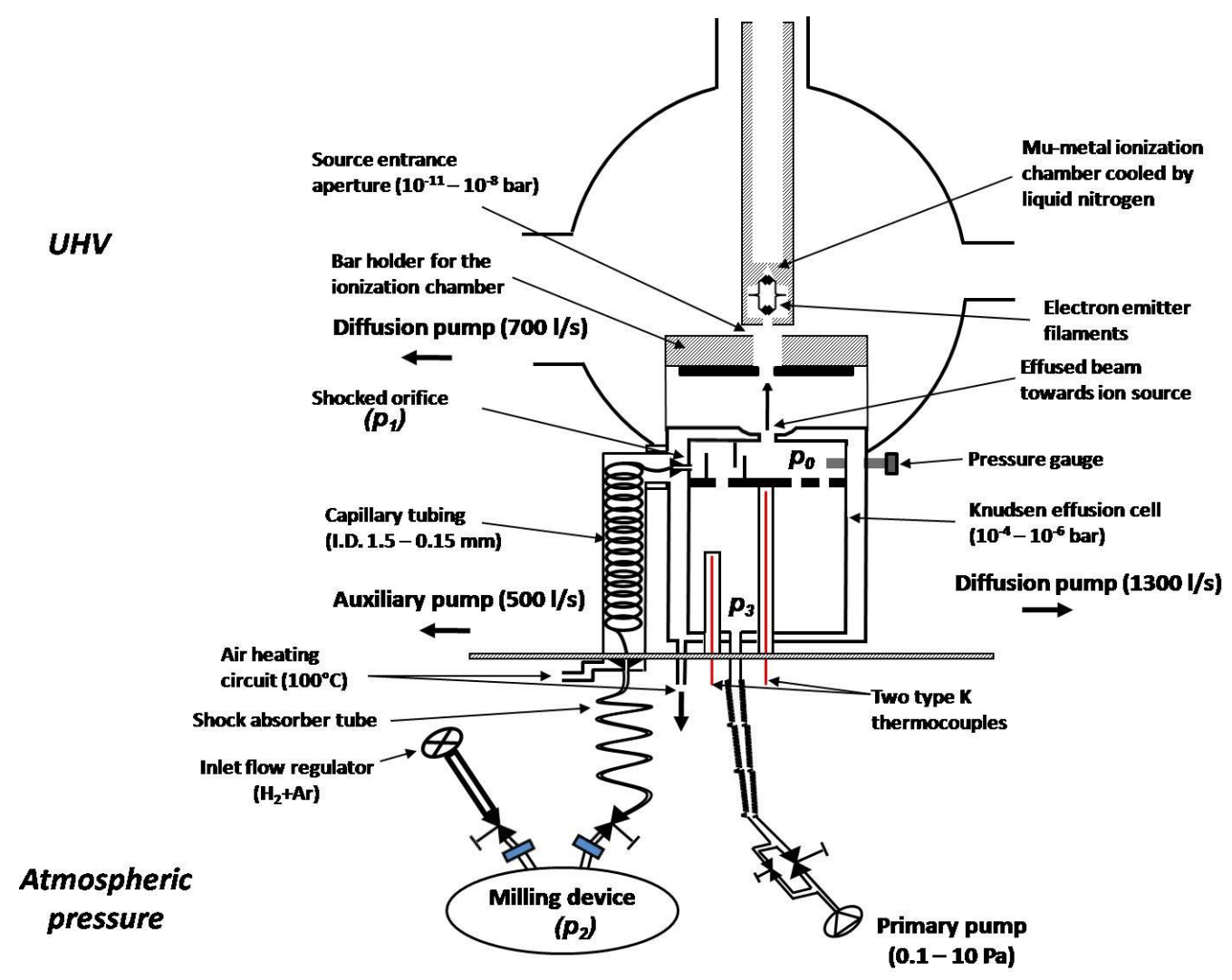

Figure 12. Schema of the coupled instruments for mass spectrometry measurements when milling the hydrides

\section{Conclusion}


The present milling reactor has been designed for two main purposes; - (i) analyse the gaseous species that are desorbed or adsorbed from powder hydrides under mechanical activation. - (ii) provide an access to kinetic constants which could be determined for the main decomposition-evaporation reactions.

Flow calculations were performed in order to propose a suitable architecture of the whole device (ballmill, capillary tubing, tubes and pipes systems, effusion cell compartment, pumping system) compatible with the mass spectrometric detection in term of effused flows. Flow simulation clearly evidenced the importance to define the flow regimes at each stage of the pipes and vessels system. This study highlights also the advantage of using a capillary for the connection between the mill and the Knudsen effusion mass spectrometer. Different working pressure conditions are associated to its length, meanwhile the diameter choice has been demonstrated to be too sensitive to be varied. Under the present experimental conditions, steady-state flow will depend mainly on the real capacity of the selected pump and thus will be adapted for optimal pressure which can be reached to form an optimized molecular beam. Any upstream pressure variation will be compensated by the evacuating pump in view of decreasing the effusion flow when the molecular beam is strong enough for mass spectrometry analysis.

\section{Acknowledgements}

This work received funding from the European Commission under COSY (EU - RTN) "Marie Curie Actions "(MRTN-CT-2006-035366). This work contributes to the research performed at CELEST (Center for Electrochemical Energy Storage Ulm-Karlsruhe). 


\section{References}

[1] Latroche M, Blanchard D, Cuevas F, El Kharbachi A, Hauback BC, Jensen TR, et al. Full-cell hydride-based solid-state Li batteries for energy storage. Int. J. Hydrogen Energy. 2019;44:7875-87.

[2] Milanese C, Jensen TR, Hauback BC, Pistidda C, Dornheim M, Yang H, et al. Complex hydrides for energy storage. Int. J. Hydrogen Energy. 2019;44:7860-74.

[3] Yartys VA, Lototskyy MV, Akiba E, Albert R, Antonov VE, Ares JR, et al. Magnesium based materials for hydrogen based energy storage: Past, present and future. Int. J. Hydrogen Energy. 2019;44:7809-59.

[4] Antiqueira FJ, Leiva DR, Zepon G, de Cunha BFRF, Figueroa SJA, Botta WJ. Fast hydrogen

absorption/desorption kinetics in reactive milled Mg-8 mol\% Fe nanocomposites. Int. J. Hydrogen Energy. 2020;45:12408-18.

[5] Cortez JJ, Castro FJ, Troiani HE, Pighin SA, Urretavizcaya G. Kinetic improvement of H2 absorption and desorption properties in $\mathrm{Mg} / \mathrm{MgH} 2$ by using niobium ethoxide as additive. Int. J. Hydrogen Energy.

2019;44:11961-9.

[6] Shevchenko YN, Mal'tseva NN, Nazarenko VA, Kedrova NS, Kuznetsov NT. Mass-spectrometric study of transformations of LiBH/sub 4/ on heating in vacuo. Journal Name: Dokl. Phys. Chem. (Engl. Transl.); (United States); Journal Volume: 290:4-6; Other Information: Translated from Dokl. Akad. Nauk SSSR; 290: No. 4-6, 1426-1430(Oct 1986). 1987:Medium: X; Size: Pages: 968-70.

[7] Ihle HR, Wu CH. Mass spectrometric Knudsen effusion measurements of vapor species in the lithiumhydrogen system. Proc. Symp. Fusion Technol., 7th Grenoble. Luxembourg: EC, Center for Information and Documentation; 1973. p. 89-97.

[8] Derdziuk J, Malinowski PJ, Jaroń T. Synthesis, structural characterization and thermal decomposition studies of (N2H5)2B12H12 and its solvates. Int. J. Hydrogen Energy. 2019;44:27030-8.

[9] Morland P, Chatillon C, Rocabois P. High temperature mass spectrometry using the Knudsen effusion cell : I Optimization of sampling constraints on the molecular beam. High Temperature and Materials Science. 1997;37:167-87.

[10] Juillet C, Tupin M, Martin F, Auzoux Q, Berthinier C, Miserque F, et al. Kinetics of hydrogen desorption from Zircaloy-4: Experimental and modelling. Int. J. Hydrogen Energy. 2019;44:21264-78.

[11] Bösenberg U, Doppiu S, Mosegaard L, Barkhordarian G, Eigen N, Borgschulte A, et al. Hydrogen sorption properties of MgH2-LiBH4 composites. Acta Mater. 2007;55:3951-8.

[12] Ar I, Güler ÖU, Gürü M. Synthesis and characterization of sodium borohydride and a novel catalyst for its dehydrogenation. Int. J. Hydrogen Energy. 2018;43:20214-33.

[13] Chatillon C. La spectrometrie de masse a haute temperature: donnees accessibles et developpements recents. Revue de métallurgie(Paris). 1998;95.

[14] Henriksen M, Gaathaug AV, Lundberg J. Determination of underexpanded hydrogen jet flame length with a complex nozzle geometry. Int. J. Hydrogen Energy. 2019;44:8988-96.

[15] Bianchi D, Joly J-P, Perrard A. Transfert des gaz pour l'analyse quantitative par spectrométrie de masse. Le Vide, Science,Technique et Applications. 1997;286:533-55.

[16] Santeler DJ. Exit loss in viscous tube flow. Journal of Vacuum Science \& Technology A: Vacuum, Surfaces, and Films. 1986;4:348-52.

[17] Hertz H. Ann. Physik. 1882;17:177.

[18] Clausing P. The Flow of Highly Rarefied Gases through Tubes of Arbitrary Length. Journal of Vacuum Science and Technology. 1971;8:636-46.

[19] Santeler DJ. New concepts in molecular gas flow. Journal of Vacuum Science \& Technology A: Vacuum, Surfaces, and Films. 1986;4:338-43.

[20] Cole RJ. Progress in Astronaut. and Aeronaut. 1976;51:261.

[21] Henry RP. Cours de science et technique du vide1968.

[22] Drowart J, Chatillon C, Hastie J, Bonnell D. High-temperature mass spectrometry: Instrumental techniques, ionization cross-sections, pressure measurements, and thermodynamic data (IUPAC Technical Report). Pure Appl. Chem. 2005;77:683-737.

[23] Chatillon C, Heyrman M. Surface reactivity by gas introduction in Knudsen cell mass spectrometry. J. Phys. Chem. Solids. 2005;66:488-93.

[24] DeMuth SF, Watson JS. Prediction of flow rates through an orifice at pressures corresponding to the transition between molecular and isentropic flow. Journal of Vacuum Science \& Technology A: Vacuum, Surfaces, and Films. 1986;4:344-7. 